\title{
A Working Model for Teacher Training in Computing through the Literacy from Scratch Project
}

\author{
Lawrence Williams ${ }^{1}$, Miroslava Černochová ${ }^{2}$, G. Barbara Demo ${ }^{3}$, and Sarah Younie ${ }^{4}$ \\ ${ }^{1}$ MirandaNet Fellowship, London, UK \\ ${ }^{2}$ Charles University in Prague, Czech Republic \\ ${ }^{3}$ Department of Informatics, University of Torino, Italy \\ ${ }^{4}$ De Montfort University, Leicester, UK \\ lawrencewilliams@mirandanet.ac.uk, \\ Miroslava.Cernochova@pedf.cuni.cz, barbara@di.unito.it, \\ syounie@dmu.ac.uk
}

\begin{abstract}
From September 2014, classroom teachers in the United Kingdom are required to move away from teaching ICT, towards new Programmes of Study in Computing, including computer programming. This chapter presents a developing international working model for teacher training, designed to support this major change in focus. Conceived at Brunel University, west London, ideas for the development of computer coding in the classroom were swiftly shared with colleagues at Charles University in Prague, at the University of Torino, Italy, and with De Montfort University, UK. Based on the MIT Scratch program, teacher trainers and classroom pupils are introduced to elementary block-coding, through a highly creative cross-curricular teaching and learning project called "Literacy from Scratch". This centres on the crosscurricular production of animated narratives, together with the pupils' own art work, for Sprites and Backgrounds. The project has successfully engaged pupils in computer coding from the ages of 5 through to 14 in the UK, and to 16 in Italy.
\end{abstract}

Keywords: Computing, teacher training, key competencies, creativity.

\section{The Background to the Literacy from Scratch Project (Lawrence Williams)}

From $1^{\text {st }}$ September 2014, teachers across the UK are required to begin teaching a new subject called Computing. ICT and digital literacy remain a part of this new curriculum, but there is now a new agenda involving the teaching of algorithms, programming and development, data and data representation, hardware and processing, communication and networks, as well as the former legal requirement to maintain some aspects of the teaching of information technology.

My personal concern was that this new material might be taught in schools as a very dry, and somewhat unnecessarily academic addition to the curriculum, and might not ignite the enthusiasm of our pupils. My hope, on the other hand, was that, using 
Scratch to develop the new subject of Computing, the whole approach might lead teachers back to the formerly highly-regarded creative, collaborative, and crosscurricular approach that had been sadly lost to our UK primary schools through the introduction of our National Curriculum, during the early 1990's.

Accordingly, I set out to link the newly designated Computing skills agenda with basic Literacy, by devising a new cross-curricular project called Literacy from Scratch. The original aim was for pupils to create very simple narratives, using Scratch, and then to animate their story's characters (or Sprites). I had done this kind of literacy work before, very successfully, using ICT tools. Starting at Key Stage 3 (with pupils aged 12 and 13 at Bishop Ramsey School, Ruislip Manor, London) ) I was later able to move the Scratch project down through Key Stage 2 (ages 7 to 10) and finally to much younger pupils, aged 5 years, at the Swaminarayan School in Neasden, London. The basic concept was that by focussing the pupils' attention on story-telling, a skill wellunderstood by all of our Primary teachers, the coding aspect of Scratch becomes the tool by which the narrative is enabled to unfold. The project is not, therefore, in the first instance, actually about computational thinking, but about narrative, and artistic creativity. Once the pupils are fully engaged in this well-established creative process, however, they find that the only way to present their story effectively, using Scratch, is by ensuring that all of their coding is functioning correctly. It makes for a very positive start to the process of introducing Computing into the school curriculum both at Primary and lower Secondary level. This process is recorded in detail on my supporting website for teachers at: www.literacyfromscratch.org.uk

There are substantial support materials on this site for teachers wishing to engage in the project, including examples of both pupils' and teachers' work, together with lesson plans and wider schemes of work. These materials have been produced for the project in Prague, as well as in London.

Parallel to this initiative, my colleague, Mirka Černochová, who had been teaching ICT courses at the Charles University in Prague, started to develop the Literacy from Scratch project with teacher colleagues in a local Czech primary school. Under Korunovacni Head Teacher, Tomas Komrska, pupils there effectively developed their Computing and literacy skills alongside their art and $\mathrm{Czech/English} \mathrm{language} \mathrm{lessons.}$ In counter-response to this very welcome innovation in art, we in London subsequently began to develop our pupils' artistic skills, too, as part of our narratives. The complementary teaching and learning styles are posted at: http://www. literacyfromscratch.org.uk/pedagogy/

"Literacy from Scratch" is a response, therefore, to the United Kingdom government's initiative to develop computer programming skills (formerly called Computer Science, now called Computing, and known as "informatics" elsewhere) in both the Primary phase of education (pupils aged 5 to 11) and the Secondary phase (aged 11 to 18). The project has several related aspects: it involves the reworking of Primary and Secondary Initial Teacher Education (ITE) programme, through which Postgraduate students are taught how to use the MIT Scratch programming language, to create sustained and animated narrative work. And it supports developments of innovative approaches to ICT teacher education in the Czech Republic. Wholeschool in-service training courses are another aspect currently being developed. 
Both our children, and their teachers in the UK, have already learned basic digital literacy. However, it is high time to master much more than just how to operate a computer. It is time to learn why and how to use computers for solving problems; to understand what a computer can really do to serve pupils in their learning and discovering; for acquiring knowledge and skills; how to protect themselves from the various risks lurking in a digital world; how to behave in the right way in such a huge cyberspace. In some countries, criticism of teaching focused merely on computer-user skills' development (using PowerPoint, and Word) has begun, and has been met, in the UK, by the introduction of this new Computing curriculum.

The international Literacy from Scratch team embraces Seymour Papert's ideas about children learning with computers: "Learning-by-making" (Papert and Harel, 1991) and Stager's: “technology as building material, hard fun, learning to make, taking time - proper time for the job. You can't get it right without getting it wrong." (Stager, 2007). We believe that it is very important to regard, and to introduce, Computing as a compulsory school subject, and that computational thinking is vital for children's mental development.

Merely attaining ICT literacy as an aim for school education belongs firmly in the past. It is essential to teach our children many skills: to be able to formulate problems, and to select appropriate computer tools and applications; to encourage them to be able to decide independently on the appropriate use of digital technology for problemsolving; to determine whether the problem is solvable using computers; how to collect and analyse data; how to automate data-processing and data-mining. It is, therefore, necessary to focus development on the ability to ask questions; to look for and discover links and contexts; to find relations between different phenomena or events; to inquire about what depends on what, and what does not relate to what; to explain results, and put them into contexts in relation to other facts. Equally, importance must be given to teaching pupils to be able to identify errors in their ways of working, and the processes they use, and to verify the correctness of applied methods and actions. The integration of computational thinking into the curriculum is an opportunity to develop further pupils' logical thinking. It would be a mistake if we were to develop these abilities of children entirely in subjects merely about computers, or about computer science, or as a part of a more general computing competency.

The Computing initiative, begun in the UK, has opened up a huge amount of professional discussion in the world, directed at the same ends. First to develop this project beyond the UK have been teachers in the Czech Republic, and in Italy, as follows.

\section{The Czech Perspective (Miroslava Černochová)}

As part of a recent Brunel - Charles University Erasmus agreement, and in harmony with the Brunel working model, the Charles University, Faculty of Education in Prague ICT (teacher trainers) decided to adopt, and to adapt, the UK teaching approach to Computing in education, and to develop profound links between ICT education and Art and Language education, using the "Literacy from Scratch" model. 
The Czech Republic is one of the EU countries which implemented ICT as a compulsory education area (subject) into a curriculum for Primary education (aged in 6 to 11) and Lower Secondary School (aged in 11 to 15). In Primary Education the ICT curriculum is concentrated on three main topics: Introduction into work with a computer, Searching information and communication, and Information processing and utilization. ICT education for lower secondary education is focused on two topics: Searching information and communication, and Information processing and utilization. ICT concepts and ICT user skills development predominate in the curriculum. There is no demand to develop concepts and knowledge from informatics/computer science. It depends on conditions in schools, on school management, and on ICT teacher professionalism how, in reality, ICT teaching is designed. Textbooks for ICT subjects are unavailable. The Ministry of Education of the Czech Republic doesn't co-ordinate the situation related to textbook publishing, though some teachers do write textbooks, or produce teaching materials themselves.

In the Czech Republic, there are not many ICT teachers of primary or lower secondary schools who pay attention to introducing programming, and to teaching children how to develop algorithmic thinking. A huge research project, organised by a team of researchers from the Faculty of Education at Charles University in Prague, has come to the conclusion that the majority of the Czech Lower Secondary School teachers don't distinguish between ICT and Informatics, and they have no idea what to teach within ICT as a subject. They prefer to teach how to use MS applications (such as Word, Excel, etc.) and how to search for information on the Internet. They "don't appreciate the importance of teaching programming, algorithmic thinking, or databases, ...." (Rambousek et al., 2007). There are two reasons for such an approach of the Czech teachers to teaching ICT in schools: firstly, the curriculum for Primary or Lower Secondary Schools is focused on fundamental ICT user's skill-development and their searching for information ability, and secondly, $18 \%$ of ICT teachers in Czech Lower Secondary Schools are not qualified and competent to teach ICT/Informatics.

The Faculty of Education in Prague educates, among others, ICT (ITT) teachers who will specialise in schools in the teaching of compulsory ICT Education. The MA degree study in ICT teacher education is focused mainly on the pedagogical aspects of ICT education. In the final semester, ICT (ITT) teachers are given an opportunity to manage a complex project in schools, based on a close collaboration with teachers, and to explore links across the Primary curriculum. Therefore, the idea of "Literacy from Scratch" could well be implemented at the Faculty of Education to great advantage.

Seeing the possibilities, an ICT (ITT) teacher decided to participate in the "Literacy from Scratch" project, designed by Lawrence Williams at Brunel University, and realised it at ZŠ Korunovační. He introduced its main idea to the school management and teachers. He organised a seminar for ICT teachers about programming in Scratch in order to create animated narratives.

The project contributes to developing interdisciplinary (or cross-curricular) relations between Czech/English language and literacy (animated stories), CICT Education (the development of algorithmic thinking) and Art Education (the design of 
Sprites, Backgrounds, and four sequences of a story). It fits very well with the education for pupils Year 3 to 7 (age 8 to 13). ICT teachers incorporate its idea into the school curriculum, in accordance with a methodology concerning how to develop key competencies, both in computer literacy and in language literacy.

This project will continue in $2014 / 15$ within a framework of research aimed at determining the impact of story-telling and programming in Scratch on pupils' understanding of how computer programs and a computer work. It will contribute to an effort to design and verify some approaches to the conceptual development of the principles of computer programming in Scratch in primary and lower secondary school aged pupils. This process will also be undertaken in the UK, linking the skills developed in Literacy from Scratch to the new Progression Pathways, created largely by Mark Dorling, and specifically designed to map this. See: http://community. computingatschool.org.uk/resources/1692

The project, based on a story-telling method, will be applied also in another Czech provincial basic school with children aged in 10-11 who will learn how to program Lego Mindstorms robots in Scratch. It is designed to contribute to the conceptual development of pupils' creativity. The project will enable pupils to extend their mental space, and contribute to a process of being aware, and developing an understanding of various complex content including creativity, technical and algorithmic thinking, imagination, and art design.

In addition, this more artistic, rather than literary, approach to story-telling adopted at the Korunovacni School has fed back into the Key Stage 1 curriculum work (for pupils aged 5 to 7 years) undertaken in London. An important part of the second year of the UK project development has involved Scratch stories being created by 5 and 6 year old pupils, but with much more emphasis on creating their own Sprites and Backgrounds for the stories, following the artistic Czech developments of the model. See: http://www.literacyfromscratch.org.uk/pupils/ks1.htm

The project was presented at the WCCE Conference in Poland in July 2013, where the creative aspects of the project were noted by G. Barbara Demo, from the Informatics Department at the University of Torino, Italy.

\section{The Italian Perspective (G. Barbara Demo)}

The international collaboration between the university departments in Torino, Italy, and Brunel, United Kingdom centres on the development of the project "Literacy from Scratch". The project was first designed in the UK to engage pupils in valid computer programming work, at an elementary stage, through creative story-telling. In Italy, the compelling problem with respect to Informatics in schools is in-service teacher training, a problem mirroring the situation in the Czech Republic. Accordingly, an international workshop was arranged in Torino, in order to explore how the project might be developed. The pedagogical methodology characterizing the project is based on a set of training sessions allowing a gradual approach to both programming and the basic principles of computing. Narrative work produced using Scratch has proved to be very appealing for users, and the development of the project in local primary and secondary schools in Torino, with the work supported by the 
Informatics Department of Torino University, has been very successful. Outcomes are posted on the linked web sites: www.literacyfromscratch.org.uk and http://t4t.di. unito.it/ (following T4T-2013, a virtual environment Moodle).

This section of the chapter concerns the activities related to Computing in Italy and describes how the interest which began at a presentation at the 10th WCCE, World Conference on Computer in Education, in Torun (Poland), 2013 (Williams and Černochová, 2013), became the seed for a cooperation between university departments in Torino, Italy, and the Brunel, United Kingdom. At WCCE 2013, the presentation of Lawrence Williams began with the full screen projected show of a "Solar System" story. It was amazing, because of its images and wonderful music. But it was impressive especially because those who usually teach an introduction to computer science, and to programming, are computer science specialists. Thus they tend to engage in completely different activities that are frankly not so appealing. Of course, an activity of the type, "Let's add up a set of integers and find their average" cannot capture the same level of attention for many reasons: it is short, and the images you can add are not inherent in the activity, etc. Besides, the Scratch code to build a story like the "Solar System" story is not difficult to understand, at least compared with some other programming languages which are less suitable for an introductory activity. Indeed, a captivating and original story can be implemented with very few commands, used in a repeated pattern, to produce the whole story. This aspect is important for someone new to programming, but is even more important if we think of a story-telling activity in a primary school, because the focus of the learning, for the pupil, is not on the actual coding. Rather, the pupil is developing a narrative, with characters and dialogue, and the coding is merely the tool for presenting the story in an entertaining way. This means that when difficulties arise, the pupil wants to overcome them in order to complete their story, rather than simply getting some abstract coding to work correctly. Secondary pupils in London, for example, frequently worked through school Break and Lunch times in order to complete their projects. One student in Italy decided to include dialogue in Russian!

The WCCE 2013 presentation convinced us that the story-telling direction was worthy to be investigated for introducing in-service teachers to computer science. The first in-person group meeting happened during the 2013 workshop Teachers for Teachers, where one of the activities was based on integrating Lawrence Williams' UK experience in story-telling using Scratch, with the activities developed in schools by Italian teachers, together with university researchers. T4T workshops are offered yearly, and involve hands-on activities based on the co-operation between university researchers and teachers in all education levels. The main concern of the collaboration is to face the challenge of finding ways to introduce computing in schools appropriate to the ages of the students involved, as well as to the teachers' competences. Indeed, nowadays we face a very peculiar time for informatics education. Till now, Informatics has been taught to students at university level, in technical schools or in vocational schools specializing in computer science. Today, Informatics is going to be taught to:

- schoolchildren who are much younger than previous students, and who have teachers not specialized in Informatics (sometimes knowing very little of it)

- students in secondary school who will not specialize in computer science 
To face this new situation, an original pedagogy in Computing must be devised through a common project carried out by researchers in pedagogy and in computer science, because both qualifications are needed. Also, best practices already present in schools for several years must be taken into account, because some teachers have done excellent activities for a development of informatics in education. Alessandro Rabbone, for example, is a teacher involved in both T4T 2012 and again in T4T 2013. This is because for almost thirty years he has introduced computer science both to his pupils in primary schools, and to his colleagues from different types of schools.

The T4T project is encouraging the development of the informatics skills of the teachers involved, and others are coming to subsequent meetings. The success of T4T can be seen in several activities begun in the area which the Informatics Department of the University of Torino is proposing. The most appreciated aspect of the project is its pedagogical methodology, with the decision to focus on hands-on activities involving story-telling as an introduction to computer science, following the UK and Czech models.

The introduction to computing competencies of the T4T-2013 workshop has been attended mainly by primary and middle school teachers, but also by professors of non-scientific disciplines in secondary schools: art, history, and literature professors were present. Professors of scientific disciplines are still missing, probably because most of them consider that digital literacy is already sufficiently well-established in education. In general also, history of philosophy professors seem to be far from paying attention to basic informatics principles, though their discipline should be conditioned by the digital culture. Further developments of T4T activities are underway, and others are planned in order to reach out to these missing teachers.

For further steps toward enriching computing competencies, the Scratch project of facilitating telling stories described in the paper by Demo and Williams, 2014, is exploited by presenting the experiences of the pupils' everyday lives as Scratch stories", in activities under development described in the report "Telling our own stories". By means of these activities, one can realize how expressing some behaviour in Scratch is close to the way one normally would describe his/her own behaviour in everyday life. In so doing, we naturally come to express daily life through branching and interactive stories thus progressing abilities in programming competencies. This idea is currently being developed at Brunel University.

The T4T collaboration around story-telling using Scratch deserves a concluding remark. The common approach turns out to integrate two directions and motivations of activity, each one characterizing the university departments involved:

- developing a narrative, with characters and dialogue, using a tool for presenting the story in an entertaining way, and making possible the implementation of the planned story in a relatively easy way, and in a short space of time, from the very start of using the new tool.

- proposing a first approach to programming, producing meaningful and entertaining results, the narratives easily provide, faster than with other programming environments, a natural basis for computer science.

- The several kinds of computing activities using Scratch for teachers and students in different types and levels of schools are described in the proceedings of the ISSEP Conference in Istanbul September 2014 (Demo and 
Williams, 2014). This paper is about introducing 8-9 to 16 years old students to several aspects of computing such as: algorithmic thinking, problem structuring, introduction to algorithms, properties particularly relevant to understanding algorithmic complexity.

We are currently trying to enlarge the working group. Indeed, other projects are starting in the Torino area with activities of the same type of those here described. The integration of these efforts will promote a larger spreading of computer science among teachers, and consequently across all phases of education.

\section{$4 \quad$ MESH - A Global Perspective (Sarah Younie)}

A further development of the Literacy from Scratch project is through the MESH initiative. See: http://www.meshguides.org/about-mesh/\#how-mesh-operates

MESH - Mapping and Managing Educational Specialist Knowhow is an educational knowledge management system with the aim of underpinning professional judgment with evidence. MESH uses an accessible multimedia mindmap approach to present a diagrammatic database of subject-specific research-based knowledge about the teaching and learning of topics across the curricular disciplines. MESH builds upon existing portals and evidence bases for education, with the aim of summarising and making accessible the existing evidence whilst also documenting gaps in knowledge and mapping points of contention. The approach is inspired by the resources available to professionals and academics in other disciplines such as health, but recognises the challenges that education has as 'a discipline across disciplines'. Wikipedia provides an example of how easily searchable a large database can be and that, over time, and through collaborative effort to pool knowledge, a high quality result may be achieved. The Map of Medicine Healthguides is also a well-developed example of software which supports mapping professional knowledge.

Much research-based knowledge is currently buried in theses, held by individual academics and teachers or published in academic journals and reports, which are not easily accessible to teachers. MESH provides a way for teachers to access this knowledge, so that it can be leveraged to improve student outcomes. MESH provides the e-infrastructure to support worldwide collaborative work between those who want to strengthen the educational evidence base and support teaching becoming a strongly evidence-based profession.

Developing research-informed practice is a challenge for educators, not least because published educational research is rarely focused on the knowledge teachers need to improve educational outcomes. MESH is being developed by a world-wide network of educators who want to make this happen. It is currently being developed at Bedfordshire University to support Literacy from Scratch as part of a coherent approach to teaching and learning using Scratch for cross-curricular work.

The present writers all see the collaboration between the various countries involved in developing this whole new model as a vital step in providing support for teachers who are setting out to promote effective, meaningful, and, above all, engaging lessons in Computing. 


\section{Conclusions}

- The Literacy from Scratch web site provides creative Computing materials for teachers of pupils aged 5 years to 14 years.

- $\quad$ The World Ecitizens web site provides an opportunity for pupils to publish and share their creative learning outcomes in Computing.

- $\quad$ MESH provides the pedagogical underpinnings for the project, with papers published and categorised, for easy access and use by teachers.

- In London, Primary teachers are being trained to develop their own skills in Computing, ready to introduce this into their classrooms, by September 2014. This includes the creation of increasingly complex Branching Stories, and interactive resources for their classrooms.

- In Prague, developments are under way, to continue widening the artistic and Computing aspects of the project.

- In Torino, teachers are being supported in developing creative, collaborative, and cross-curricular approaches to their training needs in Computing.

Much remains to be done, but this learning model has begun very successfully. To support this project, there is a new text, "Introducing Computing: a guide for teachers" as well as the Literacy from Scratch web site.

\section{References}

1. Barbara Demo, G., Williams, L.: The Many Facets of Scratch. In: Proceedings of the ISSEP Conference 2014, Istanbul (September 2014)

2. Papert, S., Harel, I.: Situating Constructionism (1991), http://www.papert.org/ articles/SituatingConstructionism.html

3. Rambousek, V., et al.: Výzkum informacní výchovy na základních školách. 1. vydání. Plzen: Koniáš, 360 s. (2007) ISBN 80-86948-10-2

4. Stager, G.: An Investigation of Constructivism in the Maine Youth Centre. Informatics in Education - An International Journal 6(2) (2007)

5. Williams, L., Černochová, M.: Literacy from Scratch. In: Proceedings of the 10th IFIP World Conference on Computers in Education, WCCE 2013, pp. 17-27. Copernicus University, Torun (2013), For a supporting text for teachers, as a guide to the project, see:

6. Williams, L. (ed.): Introducing Computing: A guide for teachers. Routledge (August 2014), http: / / www. routledge.com/books / details/9781138022850/

7. The web site with Literacy from Scratch teaching materials is to be found at, http: / / www. literacyfromscratch.org.uk 